\title{
Genome-Wide Association Study and Identification of Candidate Genes for Nitrogen Use Efficiency in Barley (Hordeum vulgare L.)
}

OPEN ACCESS

Edited by:

Hanwei Mei,

Shanghai Agrobiological Gene Center,

China

Reviewed by:

Michael Baum,

International Center for Agricultural Research in the Dry Areas (ICARDA),

Morocco

Meixue Zhou,

University of Tasmania, Australia

*Correspondence: Chengdao $L$

C.Li@murdoch.edu.au

Specialty section:

This article was submitted to

Plant Breeding,

a section of the journal

Frontiers in Plant Science

Received: 12 June 2020

Accepted: 18 August 2020

Published: 04 September 2020

Citation:

Karunarathne $S D$, Han $Y$, Zhang $X-Q$,

Zhou G, Hill CB, Chen K, Angessa T

and Li C (2020) Genome-Wide

Association Study and Identification

of Candidate Genes for Nitrogen

Use Efficiency in Barley

(Hordeum vulgare L.).

Front. Plant Sci. 11:571912.

doi: 10.3389/fp/s.2020.571912
Sakura D. Karunarathne ${ }^{1,2}$, Yong Han ${ }^{1,2}$, Xiao-Qi Zhang ${ }^{1,2}$, Gaofeng Zhou ${ }^{1,2,3}$, Camilla B. Hill ${ }^{1,2}$, Kefei Chen ${ }^{4}$, Tefera Angessa ${ }^{1,2}$ and Chengdao Li $^{1,2,3 *}$

${ }^{1}$ Western Barley Genetics Alliance, College of Science, Health, Engineering and Education, Murdoch University, Perth, WA, Australia, ${ }^{2}$ Western Australian State Agricultural Biotechnology Centre, Murdoch University, Perth, WA, Australia,

${ }^{3}$ Department of Primary Industries and Regional Development, Government of Western Australia, Perth, WA, Australia,

${ }^{4}$ SAGI West, Faculty of Science and Engineering, Curtin University, Perth, WA, Australia

Nitrogen $(\mathrm{N})$ fertilizer is largely responsible for barley grain yield potential and quality, yet excessive application leads to environmental pollution and high production costs. Therefore, efficient use of $\mathrm{N}$ is fundamental for sustainable agriculture. In the present study, we investigated the performance of 282 barley accessions through hydroponic screening using optimal and low $\mathrm{NH}_{4} \mathrm{NO}_{3}$ treatments. Low-N treatment led to an average shoot dry weight reduction of $50 \%$, but there were significant genotypic differences among the accessions. Approximately $20 \%$ of the genotypes showed high (>75\%) relative shoot dry weight under low- $\mathrm{N}$ treatment and were classified as low- $\mathrm{N}$ tolerant, whereas $20 \%$ were low- $N$ sensitive ( $\leq 55 \%)$. Low- $N$ tolerant accessions exhibited well-developed root systems with an average increase of $60 \%$ in relative root dry weight to facilitate more $\mathrm{N}$ absorption. A genome-wide association study (GWAS) identified 66 significant marker trait associations (MTAs) conferring high nitrogen use efficiency, four of which were stable across experiments. These four MTAs were located on chromosomes $1 \mathrm{H}(1), 3 \mathrm{H}(1)$, and $7 \mathrm{H}(2)$ and were associated with relative shoot length, relative shoot and root dry weight. Genes corresponding to the significant MTAs were retrieved as candidate genes, including members of the asparagine synthetase gene family, several transcription factor families, protein kinases, and nitrate transporters. Most importantly, the highaffinity nitrate transporter 2.7 (HvNRT2.7) was identified as a promising candidate on $7 \mathrm{H}$ for root and shoot dry weight. The identified candidate genes provide new insights into our understanding of the molecular mechanisms driving nitrogen use efficiency in barley and represent potential targets for genetic improvement.

Keywords: nitrogen, barley, genome-wide association study, marker trait associations, candidate genes, yield 


\section{INTRODUCTION}

Nitrogen is one of the most important macro nutrients required for vegetative and reproductive development of crops, which is naturally available in soil yet applied exogenously to improve yield. However, only about $30-50 \%$ proportion of this exogenous $\mathrm{N}$ is absorbed by plants while the rest is leached into the environment leading to water, soil, and air pollution and is a contributor to global warming (Glass et al., 2002; Anbessa and Juskiw, 2012; Chien et al., 2016). In addition, application of exogenous $\mathrm{N}$ increases production costs. Improving nitrogen use efficiency (NUE) therefore requires more attention. Nitrogen use efficiency is generally defined as the grain yield per unit of $\mathrm{N}$ available (Moll et al., 1982). There are two major approaches to improving NUE, (1) conventional breeding techniques and (2) transgenic breeding approaches. There is strong evidence in rice, wheat, and canola to support conventional breeding methods for NUE improvement under various regimes of $\mathrm{N}$ availability (Kessel et al., 2012; Kowalski et al., 2016; Neeraja et al., 2019; Stahl et al., 2019). Similarly, overexpression and modification of genes through various transgenic approaches have led to NUE improvement in rice and wheat (Hu et al., 2018; Wang W. et al., 2018). Null mutations in ARE1 gene in rice improved NUE and yield under low-N (Wang Q. et al., 2018).

Barley is a major raw ingredient for the malting and brewing industries and is widely used as a livestock feed with a small yet increasing proportion entering the human consumption market. Due to its diploid nature, it is a good genetic model for other cereal crop species in the Triticeae tribe (Poourkheirandish and Komatsuda, 2007). It has become the subject of extensive quantitative trait loci (QTL) analysis targeting important agronomic and morphologic traits such as plant height, heading date, 1,000 grain weight, grain size and yield among others (Kindu et al., 2014; Pauli et al., 2014; Watt et al., 2019). However, only a handful of studies have detected QTL for yield of plants grown under different $\mathrm{N}$ treatments (Mickelson et al., 2003; Kindu et al., 2014). Recently, 15 QTLs related to NUE and its component traits such as $\mathrm{N}$ harvest index, $\mathrm{N}$ utilization of grains and aboveground biomass, and $\mathrm{N}$ uptake efficiency were identified in a Prisma $\times$ Apex mapping population (Kindu et al., 2014). However, most of these studies are limited by low genetic diversity, low marker density, and small population sizes.

Nitrogen use efficiency is a complex polygenic trait making its genetic dissection challenging. Genome-wide association studies (GWAS) are a common approach to dissect the genetic basis of complex traits (Risch and Merikangas, 2007) and have been used successfully to identify genomic regions contributing to numerous traits in many crop species (Wang et al., 2012; Monostori et al., 2017; Hazzouri et al., 2018). In barley, complex traits such as drought resistance, salt tolerance, and frost tolerance have been the focus of GWAS (Pasam et al., 2012; Visioni et al., 2013; Hazzouri et al., 2018; Jabbari et al., 2018; Pham et al., 2019; Mwando et al., 2020). GWAS have been conducted in wheat and rice to investigate NUE (Monostori et al., 2017; Tang et al., 2019) but not yet in barley. Hydroponic screening is an effective approach for nutrient-related studies and can accurately reflect $\mathrm{N}$ and $\mathrm{P}$ uptake efficiency traits (Liu et al., 2017).

Genes responsible for potential NUE improvement have been extensively studied in rice and wheat (He et al., 2015; Wang W. et al., 2018; Hu et al., 2019; Zhang et al., 2019). Ammonium (AMT) and nitrate (NRT1/NRT2) transporters were found to play important roles in $\mathrm{N}$ uptake and transport. Overexpression of OsNRT1.1 and OsNRT2.1 in rice increased NUE, grain yield, and plant growth (Huang et al., 2017; Wang W. et al., 2018). In addition, an amino acid biosynthesis gene alanine aminotransferase incorporated from barley (HvAlaAT) into rice increased yields considerably under low- $\mathrm{N}$ treatment (Shrawat et al., 2008; Selvaraj et al., 2017). Several transcription factors and protein kinases were reported to be involved in the plant N regulatory network (Yang et al., 2014; Goel et al., 2018; Hsieh et al., 2018). Many studies suggest that manipulation of genes for primary and secondary $\mathrm{N}$ assimilatory pathways is also an effective strategy to improve NUE (Martin et al., 2006; Pathak et al., 2008; Pathak et al., 2011).

In the present study, a hydroponics screen was carried out using a set of 282 genetically diverse barley accessions under different $\mathrm{N}$ concentrations to determine the genotypic performance under suboptimal $\mathrm{N}$ conditions. GWAS was conducted using single nucleotide polymorphism (SNP) and diversity arrays technology (DArTseq) markers to detect the significant marker trait associations with NUE related traits such as shoot length (plant height), root length, shoot dry weight, root dry weight, number of tillers, and number of leaves at seedling stage. Several candidate genes were identified that can be validated in further experiments to improve the NUE of barley.

\section{MATERIALS AND METHODS}

\section{Plant Materials and Experimental Design}

A set of 282 barley accessions (listed in Supplementary Table S1) was used in the present study which represents a subset of a larger worldwide barley panel (Hill et al., 2019a). Comprising of germplasm from Africa, Asia, Australia, Europe, Middle East, North and South America including two-rowed (87\%) and sixrowed (13\%) head types with spring, winter, and facultative growth habits. They were grown hydroponically under two N treatments in controlled conditions at Murdoch University, Western Australia in 2018 and 2019 successive winter seasons. The experiment was arranged in a balanced incomplete block design with four biological replicates of each genotype, each grown in separate hydroponic containers.

\section{N Treatment and Phenotyping}

Seeds were germinated on sterilized moist Whatman No.1 filter papers in Petri dishes. At the second leaf stage (7-10 days since germination), seedlings with uniform growth status were transplanted onto $27 \mathrm{~L}$ black containers. The plants were treated with a modified Hoagland nutrient solution (Han et al., 2018) containing $2 \mathrm{mmol} / \mathrm{L} \mathrm{NH}_{4} \mathrm{NO}_{3}, 0.4 \mathrm{mmol} / \mathrm{L} \mathrm{MgSO}_{4}, 0.3$ 
$\mathrm{mmol} / \mathrm{L} \mathrm{K}_{2} \mathrm{SO}_{4}, 0.2 \mathrm{mmol} / \mathrm{L} \mathrm{KH}_{2} \mathrm{PO}_{4}, 0.4 \mathrm{mmol} / \mathrm{L} \mathrm{CaCl}, 0.19$ $\mu \mathrm{mol} / \mathrm{L} \mathrm{CuSO}_{4}, 46.9 \mu \mathrm{mol} / \mathrm{L} \mathrm{H}_{3} \mathrm{BO}_{3}, 4.5 \mu \mathrm{mol} / \mathrm{L} \mathrm{MnCl}_{2}, 1 \mu \mathrm{mol} /$ $\mathrm{L} \mathrm{Na}_{2} \mathrm{MoO}_{4}, 0.38 \mu \mathrm{mol} / \mathrm{L} \mathrm{ZnSO}_{4}, 19.9 \mu \mathrm{mol} / \mathrm{L} \mathrm{Fe}$ (III)EDTA. The $\mathrm{pH}$ of the solution was adjusted to $5.8 \pm 0.1$ with $\mathrm{NaOH}$.

The two $\mathrm{N}$ treatments, $0.2 \mathrm{mmol} / \mathrm{L} \mathrm{NH}_{4} \mathrm{NO}_{3}$ (low-N) and 2 $\mathrm{mmol} / \mathrm{L} \mathrm{NH}_{4} \mathrm{NO}_{3}$ (optimal-N, as a control) were initiated after 7 days of seedling transplanting. The nutrient solution was continuously aerated with pumps and renewed twice a week. After 3 weeks of $\mathrm{N}$ treatments leaf yellowing (LY), number of leaves (LN), number of tillers (TN), root and shoot lengths (RL, $\mathrm{SL}$ ) were recorded. Plants with uniform growth status were subsequently harvested as replicates and separated into roots and shoots and dried in the oven at $50^{\circ} \mathrm{C}$ for 3-4 days to obtain the dry weight (RDW, SDW).

\section{Calculation and Statistical Analysis}

Relative number of tillers (Rtillers), relative number of leaves (Rleaves), relative root length (RRL), relative shoot length (RSL), relative root dry weight (RRDW), and relative shoot dry weight (RSDW) were expressed as percentages;

$$
(x / y) \times 100
$$

where $x$ is the average of the phenotypic trait under low- $\mathrm{N}$, and $y$ is average of the phenotypic trait under optimal-N. The best linear unbiased estimates (BLUE) values for each trait, from four replicates and two independent experiments were used to identify the marker-trait associations. Analysis of BLUE was performed in $\mathrm{R}$, and correlations between phenotypic traits across two years were calculated using IBM SPSS Statistics Version 24.

\section{Population Structure Analysis}

The software STRUCTURE (version 2.3; Hubisz et al., 2009) was used to determine the underlying population structure in the diversity panel. Genotypes of the accessions were imported into STRUCTURE. Ten independent structure runs were performed with 30,543 DArTseq and SNP markers applying the admixture model. A burn-in period of 5,000 iterations followed by 5,000 Markov Chain Monte Carlo iterations was set for accurate parameter estimates. The number of populations (K) was set from 1 to 10 . K was determined based on the method described by Evanno et al. (2005).

\section{Linkage Disequilibrium Analysis}

Genome-wide LD (linkage disequilibrium) analysis was performed using the LD function in TASSEL (version 5.0) software (Bradbury et al., 2007). The analysis comprised of squared allele frequency correlation $\left(\mathrm{R}^{2}\right)$ and normalized coefficient of linkage disequilibrium (DPrime). The locus was considered as significant LD at $\mathrm{p}<0.05$. To estimate the LD decay, $\mathrm{R}^{2}$ values were plotted against the physical distance between the markers, and a LOESS (locally estimated scatterplot smoothing) curve was fitted using IBM SPSS Statistics Version 24. The interception of the LOESS curve and background LD was considered as an estimate of LD decay (Monostori et al., 2017).

\section{Genome-Wide Association Mapping and Haplotype Analysis}

The software TASSEL (version5.0) was used to conduct association mapping of low- $\mathrm{N}$ tolerance in barley. A set of 30,543 SNP and DArT markers was available for GWAS in the present study (Hill et al., 2019a; Hill et al., 2019b; Hill et al., 2020; Mwando et al., 2020). DArTseq genotyping by sequencing was performed using the DArTseq platform (DArT PL, Canberra, NSW, Australia). Information on genotype, population structure, and phenotypic traits (each measured and calculated) was imported to TASSEL. Association analysis was performed using Mixed Linear Model (MLM) model;

$$
\begin{aligned}
\text { Trait }= & \text { Population structure }+ \text { Marker effect }+ \text { Individual } \\
& + \text { Residual }
\end{aligned}
$$

The distribution of marker p-values across barley chromosomes were visualized as Manhattan plots ( $\mathrm{R}$ package qqman) with chromosome position as the $\mathrm{x}$-axis and $-\log (\mathrm{p}$ value) as the $y$-axis. False discovery rate (FDR) correction was performed using Benjamini-Hochberg method to obtain a qvalue (FDR adjusted $\mathrm{p}$ value) (Benjamini and Hochberg, 1995). Significant marker trait associations with $\mathrm{q}<0.05$ were selected. Markers within $10 \mathrm{Mb}$ were clustered into one locus based on LD decay, and the haplotypes for each locus were defined to identify beneficial haplotypes conferring high NUE. Average RSDW of the barley genotypes was used as the key parameter to represent NUE in our study (Yang et al., 2014; Xiong et al., 2019). Phenotypic effects $\left(a_{i}\right)$ of selected marker loci were calculated using the average phenotypic values for accessions harboring favorable and unfavorable alleles based on average values for the given traits across 2 years (Li et al., 2016).

\section{Identification of the Candidate Genes}

By using an in-house barley blast server BarleyVar (http://146. 118.64.11/BarleyVar/) with genomic variants from 20 barley accessions, the genes containing the significant low- $\mathrm{N}$ tolerant marker and genes between $50 \mathrm{~Kb}$ upstream and downstream of the MTAs were identified as potential candidates. They were blasted against the barley reference genome at IPK Barley BLAST Server (https://webblast.ipk-gatersleben.de/barley_ibsc/) to obtain gene annotations.

\section{RESULTS}

\section{Phenotypic Evaluation of Low-N Tolerance in Barley}

Barley seedlings started showing clear phenotypic segregation between the two $\mathrm{N}$ treatments after 3 weeks. The seedlings grown under low- $\mathrm{N}$ were smaller with thinner stems and had pale green and narrower leaves compared to seedlings grown under optimal-N (Figure 1A). Measurements of root and shoot dry weights and root and shoot lengths were used to assess performance under low-N. Based on low to high relative shoot 

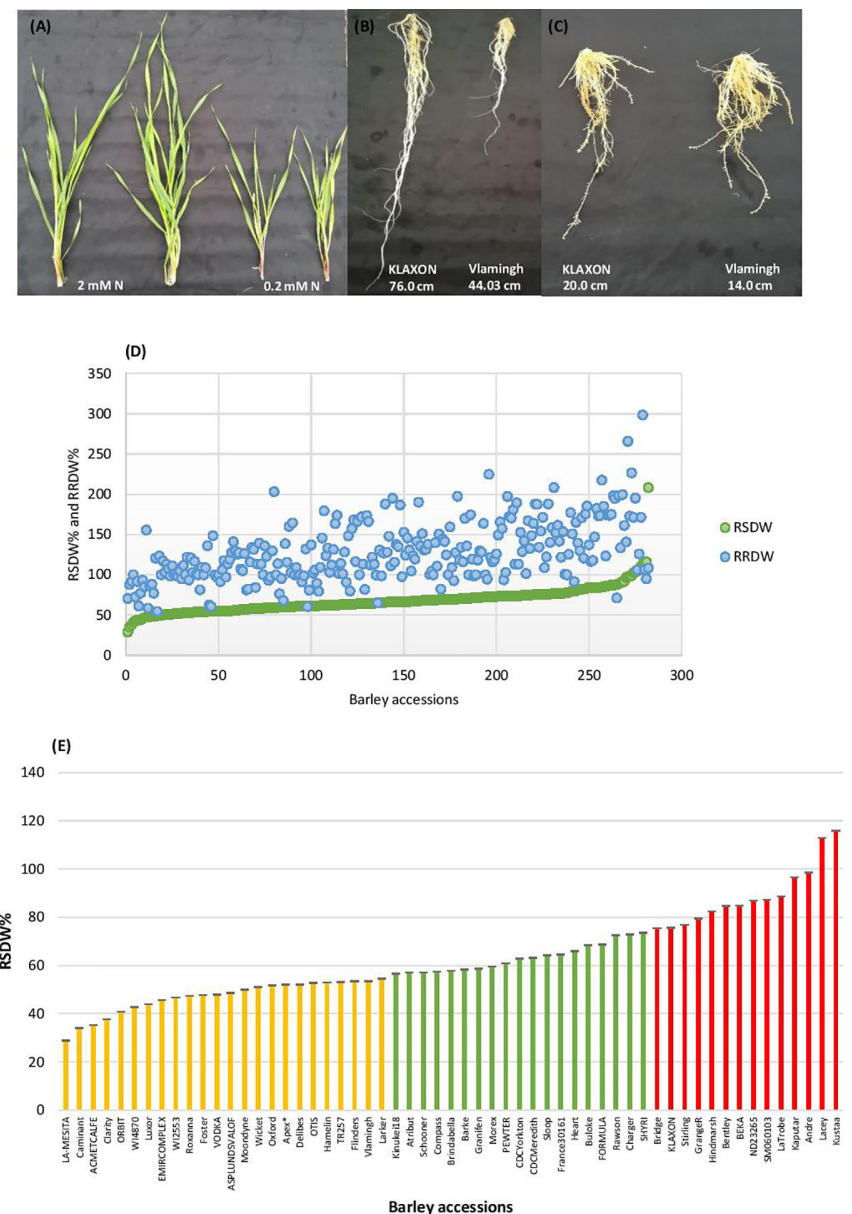

FIGURE 1 | Performance of barley genotypes under low and optimal-N conditions. (A) Shoot growth of Vlamingh under optimal-N treatment (2 mM) and low-N treatment $(0.2 \mathrm{mM})$. (B) Variation in root lengths of low- $\mathrm{N}$ tolerant KLAXON and low- $\mathrm{N}$ sensitive Vlamingh varieties under low-N (0.2 mM). (C) Root lengths of low- $\mathrm{N}$ tolerant KLAXON and low-N sensitive Vlamingh varieties under optimal-N (2 mM). (D) Distribution of relative shoot dry weight (RSDW) and relative root dry weight (RRDW) among 282 barley accessions which depicts average NUE. (E) Performance of barley genotypes based on RSDW under low-N. Yellow, Low-N sensitive; Green, Moderately tolerant to low-N; Red, Low-N tolerant. Apex* was used as a parental variety of a mapping population in Kindu et al. (2014).

and root dry weights (RSDW and RRDW), barley accessions were categorized as low- $\mathrm{N}$ sensitive, moderately tolerant, and tolerant (Table 1). Approximately $20 \%$ of the accessions were sensitive to low-N. Low-N sensitive genotypes had an average shoot dry weight reduction of $50-70 \%$, while the tolerant varieties had only a reduction of $25 \%$ under low- $\mathrm{N}$ treatment compared to optimal-N in both experiments (Supplementary Table S2). Relative root dry weight showed a wide range of variation among the genotypes under low- $\mathrm{N}$ where approximately

TABLE 1 | Cut-off values for the response of barley genotypes to low- $N$ based on relative shoot dry weight.

\begin{tabular}{lcc}
\hline Category & RSDW cut-off value & Number of barley genotypes \\
\hline Low-N sensitive & $\leq 55 \%$ & 58 \\
Moderately tolerant & $55-75 \%$ & 167 \\
Low- $N$ tolerant & $>75 \%$ & 57
\end{tabular}

$20 \%$ of accessions showed a $10-50 \%$ reduction and the others with an average increase of $60 \%$ compared to those under optimal-N. The population average for RRDW was around $150 \%$. Low- $\mathrm{N}$ tolerant varieties had $50-100 \%$ longer roots than sensitive varieties under low-N supply (Figure 1B). On the other hand, all the accessions grown under optimal-N supply had relatively short root systems, mostly ranging from 25 to $50 \mathrm{~cm}$ (Figure 1C).

Leaf yellowing was also a prominent phenotypic trait indicating low- $\mathrm{N}$ sensitivity which was scored from 0 (green) to 2 (completely yellow). None of the accessions under optimal$\mathrm{N}$ treatment exhibited leaf yellowing whereas more than $95 \%$ of the accessions showed leaf yellowing under low-N. In addition, the number of tillers and leaves were counted for both treatments. Tiller and leaf numbers were comparatively higher in low- $\mathrm{N}$ tolerant accessions than the sensitive ones under low$\mathrm{N}$. However, the number of leaves was a better indicator of low-N 
performance of the barley accessions only when considered together with other phenotypic traits such as dry weight.

Thus, based on the reduction of shoot dry weight under low$\mathrm{N}, 57$ varieties were identified as low-N tolerant (maintained $>75 \%$ RSDW compared to the control condition (optimal-N), 58 varieties were identified as low- $\mathrm{N}$ sensitive (maintained $\leq 55 \%$ RSDW) (Table 1, Figure 1D). The population average for RSDW was $65 \%$. A representative list of 57 genotypes (with the most tolerant and sensitive genotypes) which included both Australian and Canadian commercial varieties is provided in Supplementary Table S3; Figure 1E.

\section{Correlations Between Traits}

Correlation analysis was performed for all environments with two $\mathrm{N}$ treatments and two experimental years for all the phenotypic traits measured (Supplementary Table S4 and Supplementary Figure S1). There was a significant positive correlation between the two traits shoot dry weight (SDW) and root dry weight (RDW) (coefficient of correlation $\mathrm{R} \sim 0.8$ in both years) under low-N (Table 2) indicating that either of the two traits SDW or RDW can be used to score low-N tolerance at the seedling stage of barley. SDW also showed a positive correlation ( $R \sim 0.65$ in 2018 and $\mathrm{R} \sim 0.7$ in 2019) with leaf number.

\section{Analysis of Population Structure and Linkage Disequilibrium Assay}

The population structure analysis assigned the 282 genotypes used in the present study to three subpopulations $(K=3)$ with some admixture individuals in each subpopulation. The composition of each cluster is shown in Figure 2A represented by three different colors. LD was calculated for the entire population by pairwise marker $\mathrm{R}^{2}$ for each chromosome. The mean LD decay in the 282 barley accessions was $10.6 \mathrm{Mb}\left(\mathrm{R}^{2} \sim\right.$ 0.2 ). The LD decay of the population estimated as the intercept of the LOESS curve is given in Figure 2B.

\section{Marker-Trait Associations and the Beneficial Haplotypes for NUE}

Two independent GWAS were performed using data collected under low-N and optimal-N for seven phenotypic traits and their calculated relative values in both years. The significance level of the threshold for the traits with FDR correction were $P=3.19 \times$ $10^{-6}$ and $P=4 \times 10^{-5}$ with $-\log 10(\mathrm{p})$ values as 5.5 and 4.32 , respectively in 2018 and 2019.
A total of 299 markers associated with different nitrogen use efficiency (NUE) related traits: RL, SL, RDW, SDW, Rtillers, Rleaves, RRL, RSL, RRDW, RSDW were identified from 2018 and 2019 GWAS based on FDR with $\mathrm{q}<0.05$. Only the significant associations were selected from the above marker set if the markers associated with at least two phenotypic traits under low-N. Accordingly, the list was narrowed down to 136 MTAs, and it was obvious that the majority of these markers were associated with RSDW and RRDW as two key traits of NUE (Figures 2C-F).

From these significant MTAs, associated markers flanking a region of $10 \mathrm{Mb}$, based on LD decay were clustered as one MTA region which reduced the number of MTA regions to 66 (15 MTAs in 2018 and 51 MTAs in 2019) (Supplementary Tables S5 and S6). The 15 MTAs identified in 2018 were on chromosomes $1 \mathrm{H}(1), 2 \mathrm{H},(1), 3 \mathrm{H}(2), 4 \mathrm{H}(2), 5 \mathrm{H}(1), 6 \mathrm{H}(2)$, and $7 \mathrm{H}(6)$. Similarly, there were eight MTAs on chromosomes $1 \mathrm{H}$, nine on $2 \mathrm{H}, 12$ on $3 \mathrm{H}$, three on $4 \mathrm{H}$, six each on $5 \mathrm{H}$ and $6 \mathrm{H}$ and seven on $7 \mathrm{H}$ identified in 2019. Haplotypes were defined for each identified locus in both experiments and the NUE was averaged for each haplotype (Supplementary Table S5). Haplotype conferring high NUE was considered as the beneficial haplotype and subsequently as the most significant locus. For instance, MTA 44 flanked by markers L6H581687061, L6H582498713 had three main haplotypes as "AC, GC, AT" with 79, 67, and 96\% average NUE respectively (Figure 3I) where haplotype "AT" was clearly the most beneficial haplotype at this locus. The 12 most significant loci based on the haplotype analysis are presented in Figure 3. Among them, there were four stable MTAs (Supplementary Figure S2) repeatedly identified in both years for one or more traits: RSDW, RRDW, and RSL on chromosomes $1 \mathrm{H}(1), 3 \mathrm{H}$ (1) and $7 \mathrm{H}$ (2). For instance, markers L3H147608174 and L3H147608182, L3H147607703, and L3H147607706 on chromosome 3H were identified for RSDW and RRDW in both years (Supplementary Figure S2). For further analysis, these stable MTAs repeated in both years were considered.

Phenotypic effect $\left(a_{i}\right)$ was calculated for the marker loci contributing to the above four stable MTAs, and alleles for trait improvement were identified (Table 3). Alleles with positive phenotypic effects that led to the increase of RSDW, RRDW, RSL were identified as favorable alleles whereas marker alleles with negative effects were identified as unfavorable. Marker L7H004016220 (tightly linked with markers

TABLE 2 | Correlation coefficients of mean values of phenotypic traits in the 2018 and 2019 seasons.

\begin{tabular}{|c|c|c|c|c|c|c|}
\hline Low-N in 2018 \& 2019 & SL & $\mathbf{R L}$ & SDW & RDW & LN & TN \\
\hline SL & - & $.242^{\star \star}$ & $.473^{\star \star}$ & $.216^{\star \star}$ & $.127^{\star}$ & 0.058 \\
\hline RL & $.246^{\star \star}$ & - & $.388^{\star \star}$ & $.385^{\star \star}$ & $.323^{\star \star}$ & $.254^{\star \star}$ \\
\hline SDW & $.634^{\star \star}$ & $.394^{\star \star}$ & - & $.775^{\star \star}$ & $.600^{\star \star}$ & $.476^{\star \star}$ \\
\hline RDW & $.351^{\star \star}$ & $.570^{\star \star}$ & $.802^{\star \star}$ & - & $.578^{\star \star}$ & $.487^{\star \star}$ \\
\hline LN & $.170^{\star \star}$ & $.293^{\star \star}$ & $.651^{\star \star}$ & $.669^{\star \star}$ & - & $.716^{\star \star}$ \\
\hline TN & $.136^{*}$ & $.230^{\star \star}$ & $.550^{\star \star}$ & $.604^{\star \star}$ & $.642^{\star \star}$ & - \\
\hline
\end{tabular}

Below the diagonals are the correlation coefficients of phenotypic traits under low-N in 2018, and above the diagonals are the correlation coefficients of phenotypic traits under low- $N$ in 2019. *Correlation is significant at the 0.05 level. ${ }^{* *}$ Correlation is significant at the 0.01 level. (SL, Shoot length; RL, Root length; SDW, Shoot dry weight; RDW, Root dry weight; LN, Leaf number; TN, Tiller number). 

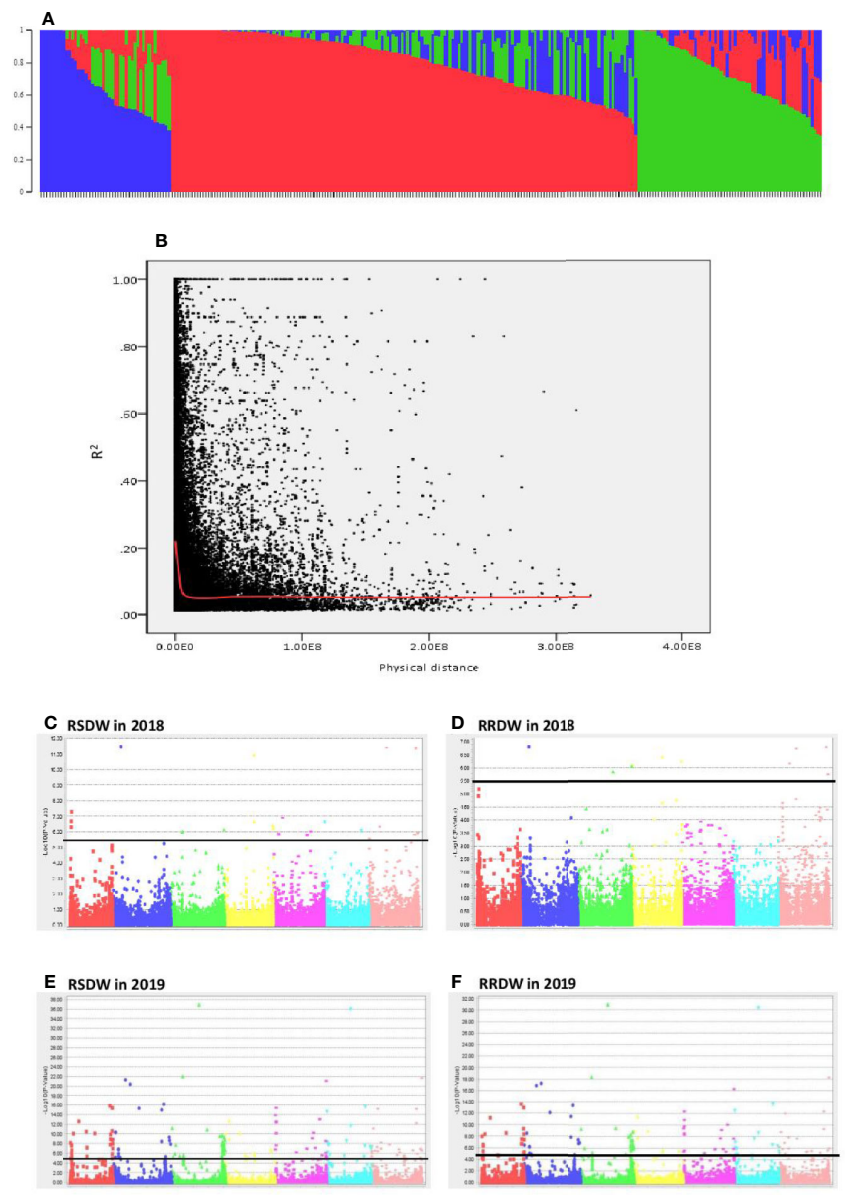

FIGURE 2 | Genome wide association study of 282 barley accessions for NUE related traits under low-N. (A) Population structure of 282 barley accessions based on genetic diversity detected using $\sim 30,000$ markers. Three subpopulations $(K=3)$ are represented using different colors, with shared colors representing admixed groups. (B) Decay of LD of the entire barley population used. The LOESS fitting curve illustrates the LD decay (red line). (C-F) Manhattan plots for relative shoot dry weight (RSDW) and relative root dry weight (RRDW) in 2018 and 2019 respectively. The horizontal axis represents the seven chromosomes $(1 \mathrm{H}-7 \mathrm{H})$ of the barley genome. The vertical axis represents $-\log _{10}(\mathrm{p}$ value $)$ of the MTAs. Horizontal black line represents the threshold value $-\log _{10}(p)=5.5$ or $-\log 10(p)=4.3$.

L7H004018128 and L7H004018104) had positive effects on RSDW and RRDW. Taken together with other phenotypic data obtained throughout the study, NUE of the genotypes with favorable alleles for RSDW and RRDW was moderate to high, and those with unfavorable alleles were low. For instance, genotypes Hindmarsh, KLAXON, and Lacey discovered as high NUE from the present study had favorable alleles for the markers L3H147608174, L3H147608182, and L7H004018104 (Table 3

TABLE 3 | Favorable alleles, phenotypic effects $\left(\mathrm{a}_{i}^{*}\right)$ and the number of accessions.

\begin{tabular}{|c|c|c|c|c|c|c|c|c|c|}
\hline Marker & $p$ value & $-\log 10(p)$ value & Trait & Chr & Ref allele & Alt allele & Fav allele & $a_{i}{ }^{*}$ value & No of accessions with fav allele \\
\hline L1H017313420 & $5.12 \mathrm{E}-07$ & 6.29 & RSDW & 1 & - & $\mathrm{T}$ & - & 1.33 & 202 \\
\hline L1H017313985 & 2.09E-07 & 6.68 & RSDW & 1 & $\mathrm{~T}$ & C & $\mathrm{T}$ & 0.29 & 213 \\
\hline L3H147608174 & 1.04E-06 & 5.98 & RSDW & 3 & $A$ & $G$ & A & 0.74 & 240 \\
\hline L3H147608182 & 1.05E-06 & 5.98 & RSDW & 3 & G & A & $G$ & 0.73 & 240 \\
\hline L7H004016220 & 2.86E-06 & 5.54 & RSDW & 7 & $\mathrm{~T}$ & C & $\mathrm{T}$ & 0.21 & 244 \\
\hline L7H004016220 & 6.81E-04 & 3.17 & RRDW & 7 & $\mathrm{~T}$ & C & $\mathrm{T}$ & 0.56 & 244 \\
\hline L7H004018104 & 4.31E-06 & 5.37 & RSDW & 7 & $A$ & $\mathrm{~T}$ & $A$ & 0.27 & 238 \\
\hline L7H004018128 & $6.54 \mathrm{E}-07$ & 6.18 & RRDW & 7 & $\mathrm{C}$ & $A$ & C & 0.52 & 243 \\
\hline L7H640049188 & 8. 41E-09 & 8.08 & RSL & 7 & $\mathrm{~T}$ & $G$ & $\mathrm{~T}$ & 0.12 & 263 \\
\hline
\end{tabular}

Ref allele is the reference allele, Alt allele is the alternate allele and Fav allele is the favorable allele, $a_{i}^{*}$ is the phenotypic effect. RSDW, relative shoot dry weight; RRDW, relative root dry weight; RSL, relative shoot length. 

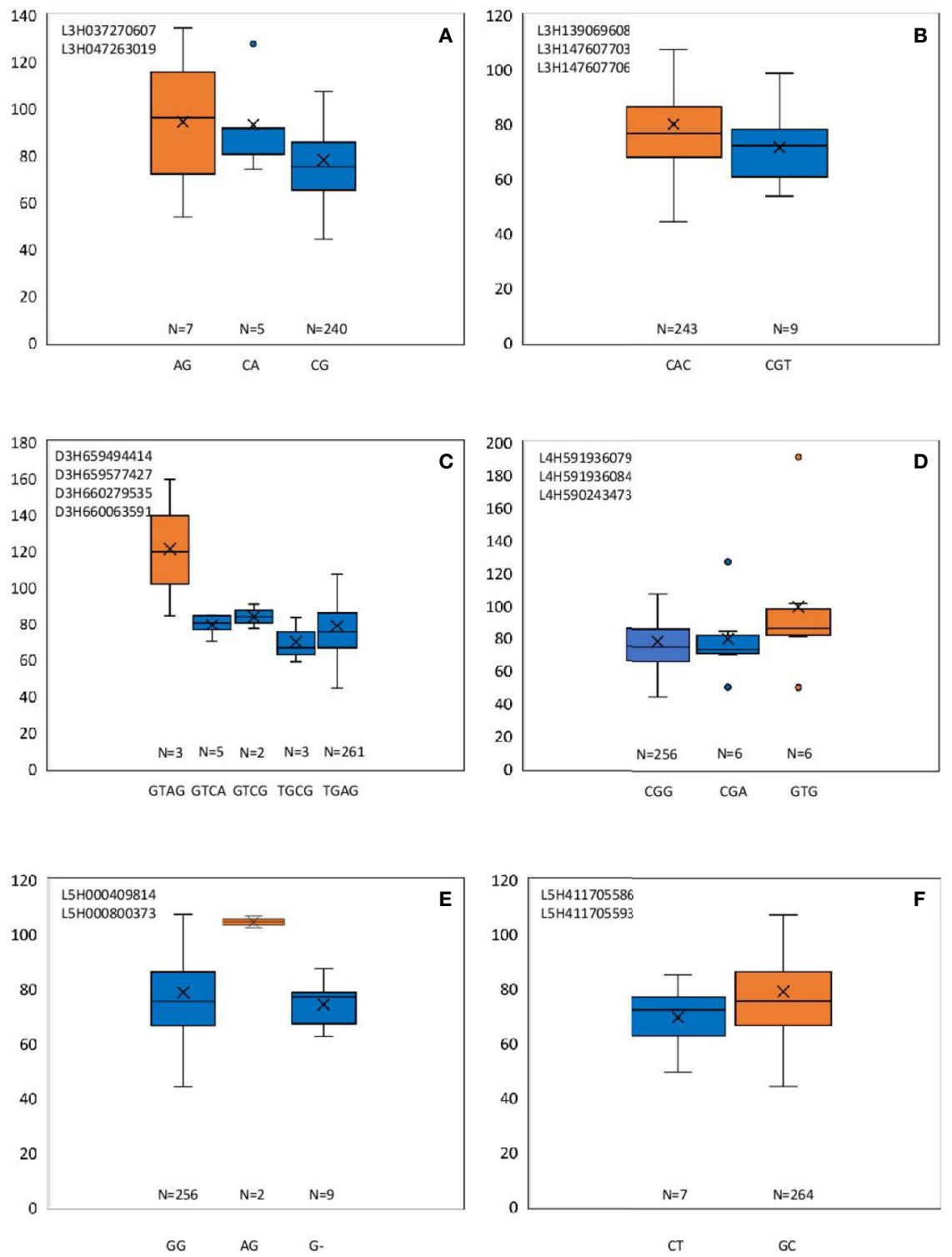

FIGURE 3 | Continued

and Supplementary Table S3). Also, high nitrogen use efficient cultivars Lacey, Hindmarsh, and Bentley had favorable alleles for L1H017313985.

\section{Candidate Genes Associated With Tolerance to Low-N}

A total of 140 candidate genes (Supplementary Table S5) were identified by aligning the significant marker positions from the 66 MTAs in the recently annotated barley reference genome (http:// 146.118.64.11/BarleyVar/\& https://webblast.ipk-gatersleben.de/ barley_ibsc/). There were 25 genes on chromosome $1 \mathrm{H}, 11$ on $2 \mathrm{H}, 39$ on $3 \mathrm{H}, 7$ on $4 \mathrm{H}, 16$ each on $5 \mathrm{H}$ and $6 \mathrm{H}$, and 26 on $7 \mathrm{H}$. Out of the 140 candidate genes located on seven chromosomes, 93 could be excluded due to the weaker associations with the QTL region or with annotated function less related to NUE. The majority of the rest 47 genes located very close to the significant markers, whereas a few of them contained the marker itself providing strong evidence for candidate gene identification (Table 4). They belonged to several functional categories, namely, protein kinases, transcription factors or other stress-related candidates while some of them had unknown functions. Most importantly, one promising candidate gene encoding high-affinity nitrate transporter 2.7 was identified on chromosomes $7 \mathrm{H}$ with close proximity to the marker C7H600147760, through BLAST-based annotation. In addition, some other strong candidate genes such as leucine-rich repeat receptor-like protein kinase family protein gene $(7 \mathrm{H})$ and an Fbox domain-containing protein gene $(7 \mathrm{H})$ aligned strongly with two of the most significant markers L7H004018173 and 

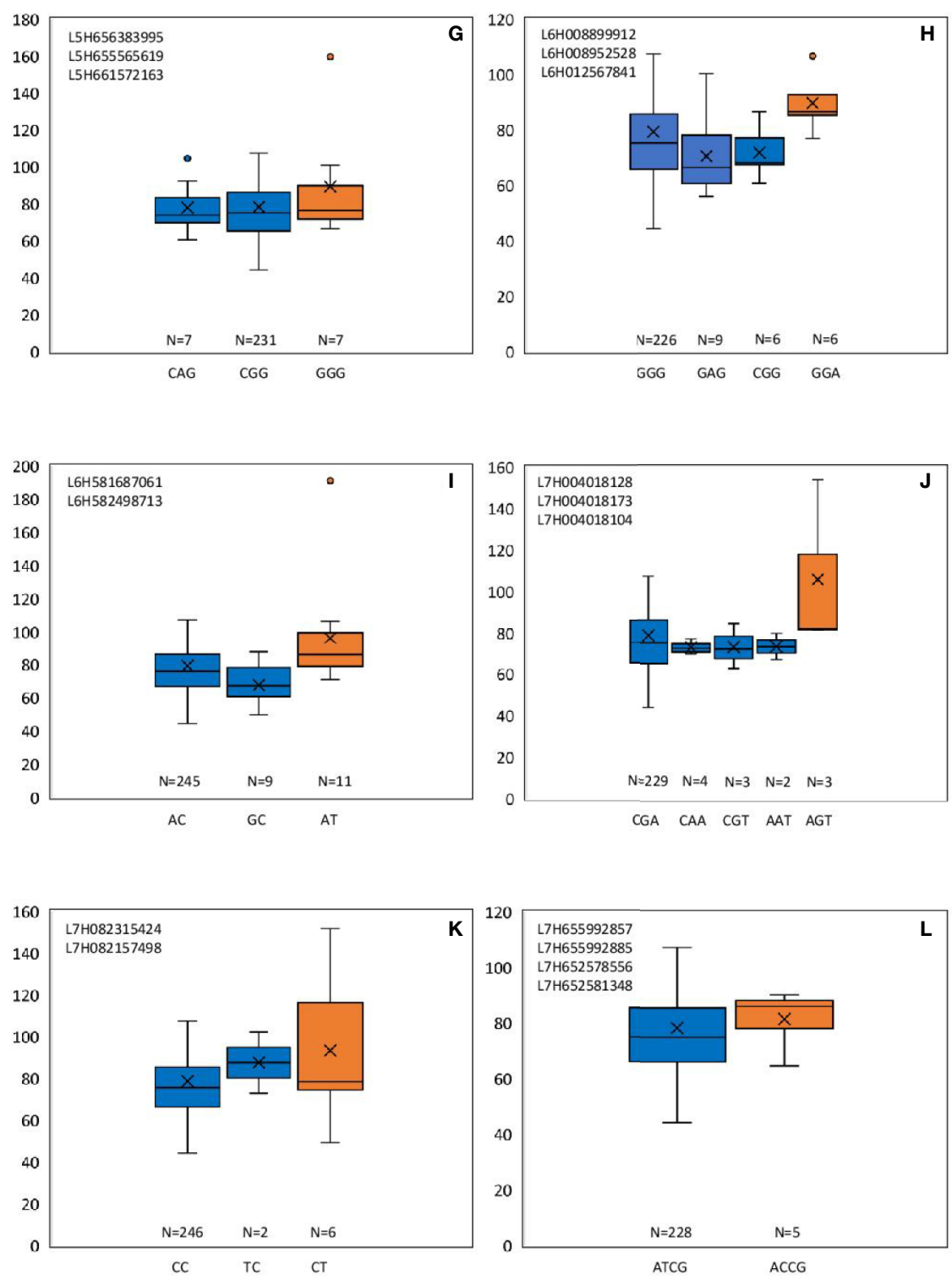

FIGURE 3 | Haplotypes defined for the most significant MTAs identified in 2018 and 2019. (A-L) Most beneficial haplotype conferring high NUE per locus is highlighted in orange. The $y$-axis indicates average NUE, and the $\mathrm{x}$-axis indicates the haplotype. $\mathrm{N}$ is the number of barley accessions represented by each haplotype.

L7H640049188, respectively (Table 4). Genes encoding asparagine synthetase 2 (D1H549784675) and sodium coupled neutral amino acid transporter (L6H502984487) might also be useful in low-N tolerance. Protein kinase superfamily protein and serine/threonineprotein kinase were repeatedly identified at different chromosomes exhibiting their involvement in low-N tolerance.

\section{DISCUSSION}

Nitrogen use efficiency is tightly related with morphological and agronomic traits such as tiller number, shoot length (plant height), root length, shoot and root dry weights, and most importantly yield (Beatty et al., 2010; Safina, 2010; Gao et al., 2017; Ghoneim et al., 2018). As yield components such as grain size and grain number per spike are difficult to determine in a larger population, our work focused mainly on the shoot and root dry weights which were promising indicators for NUE in recently conducted research (Yang et al., 2014; Xiong et al., 2019). Positive correlation between shoot and root dry weights ( $\mathrm{R} \sim 0.8$ in both years) in our study confirmed that either of the two traits can be used to score low- $\mathrm{N}$ tolerance. We conducted a hydroponic screen of 282 barley accessions to observe phenotypic changes under low-N treatment. Several studies have been carried out so far in wheat, maize, and barley using hydroponics as a screening method (Sun et al., 2013; Yang et al., 
2014; Liu et al., 2017; Ranjitha et al., 2017; Xiong et al., 2019) because of the ability to supply precise amounts of nutrients and easy observation of root characteristics. Furthermore, it has been reported that the root system architecture-related traits studied in hydroponic experiments have a positive correlation with nutrient (mainly $\mathrm{N}$ and $\mathrm{P}$ ) uptake efficiency traits (Liu et al., 2017). The six quantitative traits SDW, RDW, RL, SL, TN, LN and the qualitative trait LY scored in this study exhibited distinct changes between different genotypes under low-N. However, dry weight should be the most important parameter related to growth at the seedling stage (Yang et al., 2014). Hence, we used the relative dry weights (ratios of low- $\mathrm{N}$ to optimal-N) of shoots and roots to investigate barley's tolerance to low-N.

Root architecture parameters, such as root length and lateral root number were also prominent characteristics in all genotypes under low-N than that of optimal-N which implies their response to low- $\mathrm{N}$ by increasing their root surface area. The results reported by Tian et al. (2014) reinforce our study, finding an increase in lateral root elongation in Arabidopsis under low $\mathrm{NO}_{3}^{-}$. Similarly, exogenous $\mathrm{NO}_{3}^{-}$stimulated lateral root elongation in maize (Postma et al., 2014; Zhan and Lynch, 2015). Assessing maize recombinant inbred lines (RILs), Li et al. (2015) reported that 70\% of the QTLs for NUE, NUpE, and NUtE overlapped with QTLs controlling seedling root traits, suggesting a large contribution of morphological root traits to NUE. When available $\mathrm{N}$ is limited, the ability to absorb $\mathrm{N}$ is more important which is more related to root morphology, whereas $\mathrm{N}$ utilization becomes important than $\mathrm{N}$ absorption when available $\mathrm{N}$ is not limiting (Monostori et al., 2017), suggesting the welldeveloped root systems of low-N tolerant varieties facilitate more $\mathrm{N}$ absorption and improve plant growth under $\mathrm{N}$ limiting conditions. Specifically, the low-N tolerant varieties Granger, KLAXON, and Bridge (Supplementary Table S3) developed very large and long root systems with $\sim 70-80 \%$ increase in RRDW compared to low- $\mathrm{N}$ sensitive varieties such as Foster, Vodka, and Wicket. Besides, there were a very few high responsive genotypes (RSDW $\geq 200 \%$ and RRDW $\geq 250 \%$ ) suggesting a significantly high uptake of $\mathrm{N}$ by these plants even under low-N supply (He et al., 2017; Sigua et al., 2018). These genotypes performed well in conditions of both low and optimal$\mathrm{N}$ and might be exploitable for breeding. The varieties with intermediate tolerance to low- $\mathrm{N}$ have a strong potential for further NUE improvement and thus require further attention in future studies.

We observed a considerable number of MTAs of which the majority related to RSDW, RRDW, Rtillers, and Rleaves. Very few of these corresponded to QTLs reported in previous studies (Kindu et al., 2014). Marker L5H411705586 associated with RSDW and RRDW was located on chromosome $5 \mathrm{H}$ in this study, in close proximity to the QTL for leaf weight (Lw) described by Kindu et al. (2014) both under no-N and low-N using 94 RILs of a Prisma $\times$ Apex mapping population. Kindu et al. (2014) have also reported QTLs for plant height $(\mathrm{Ph})$ on chromosomes $1 \mathrm{H}$ and $3 \mathrm{H}$ under low-N. In accordance with these results, we observed L3H350883753 on chromosome $3 \mathrm{H}$ for RSL (similar to $\mathrm{Ph}$ ) under low- $\mathrm{N}$ in our experiment. It is difficult to compare these results as the previous study has used a barley mapping population whereas we have used a natural population. Abdel-Ghani et al. (2019) reported QTLs for shoot biomass in a diverse spring barley panel on chromosomes $3 \mathrm{H}, 4 \mathrm{H}$, and $7 \mathrm{H}$ which are in concordance with markers L3H350883746, L4H591936079, L7H082315424 identified in our study. Two other QTLs for root dry weight on chromosomes $1 \mathrm{H}$ and $2 \mathrm{H}$ and one QTL for tiller number on $7 \mathrm{H}$ under different- $\mathrm{N}$ levels overlapped with MTAs from the present study (Hoffmann et al., 2012). However, the majority of the MTAs reported in the present study have not been discovered previously to the best of our knowledge. These significant MTAs associated with NUE related traits are useful for marker-assisted selection in barley breeding programs.

Candidate genes retrieved from the significant MTAs belong to key gene families such as the asparagine synthetase (ASN) gene family, bHLH, WRKY, MADS and NAC transcription factors (TFs), protein kinases, and nitrate transporters. They have been reported as genes associated with $\mathrm{N}$ metabolism in maize, soybean, wheat, and Arabidopsis (Law et al., 2003; Hao et al., 2011; Curtis et al., 2018; Jiang et al., 2018). In our study, a gene encoding asparagine synthetase 2 (HvASN2) was identified on chromosome $1 \mathrm{H}$. A functional homolog of it was reported in maize and was shown to be downregulated under low-N (Jiang et al., 2018). Asparagine is a major $\mathrm{N}$ storage and transport compound, and asparagine synthetase acts as an important switching enzyme in $\mathrm{N}$ metabolism (Canas et al., 2010). Overexpression of ASN1 in Arabidopsis was shown to increase the $\mathrm{N}$ status of the plant and seed protein content (Law et al., 2003). TaASN1 in wheat is the most responsive gene to $\mathrm{N}$ availability compared to the alternative ASN genes; TaASN2, TaASN3, TaASN4 (Curtis et al., 2018). A marker that overlapped with HORVU1Hr1G092130, encoding a WRKY transcription factor, was identified from the present study. Similarly, ZmWRKY36 genes in maize with similar annotations to the barley WRKY gene have been reported as signaling genes which respond to abiotic and biotic stresses including low-N (Jiang et al., 2018). WRKY TFs were highly induced under low $\mathrm{KNO}_{3}$ in Brassica juncea (Goel et al., 2018).

Several other TFs; NAC-domain protein (3H), MADS-box TF $(3 \mathrm{H})$, bHLH $(1 \mathrm{H}$ and $6 \mathrm{H})$ were identified in barley under low-N. $P v N A C 1$ and $P v N A C 2$ in switchgrass were identified as positive regulators of leaf senescence and NUE (Yang et al., 2015). Overexpression of TaNAC2-5A in wheat increased the tiller and spike number, shoot and root dry weight, grain $\mathrm{N}$ accumulation, and thousand-grain weight under low-N compared to high- $\mathrm{N}$ with $\sim 10 \%$ yield improvement than the wild type. TaNAC2-5A also upregulated the expression of nitrate transporters (TaNRT2.1, TaNPF7.1) and assimilation genes (TaGS2) (He et al., 2015). Thus, this represents a good candidate gene for NUE improvement in wheat. Furthermore, rice overexpressing OsMADS25 promoted shoot length, lateral and primary root growth under $\mathrm{N}$ free conditions (Zhang et al., 2018). It could also promote the accumulation of nitrate and 
TABLE 4 | List of candidate genes for potential NUE improvement in barley.

\begin{tabular}{|c|c|c|c|c|c|}
\hline Trait & Gene & Chr & Marker & Start-End & Annotation \\
\hline Rleaves, RRL, Rtillers, RSDW & HORVU1Hr1G033980 & 1 & $\begin{array}{l}\text { L1H217665224, } \\
\text { L1H217665227, } \\
\text { L1H217665220 }\end{array}$ & $218377991-218379496$ & Transcription factor bHLH140 \\
\hline Rleaves, RSL, RRDW, RSDW & HORVU1Hr1G024420 & 1 & L1H112101141 & $111584928-111590266$ & Asparagine-tRNA ligase \\
\hline $\begin{array}{l}\text { Rleaves, Rtillers, RRDW, } \\
\text { RSDW }\end{array}$ & $\begin{array}{l}\text { HORVU1Hr1G092130, } \\
\text { HORVU1Hr1G092110 }\end{array}$ & 1 & $\begin{array}{l}\text { D1H549784675, } \\
\text { D1H549810050 }\end{array}$ & $\begin{array}{l}549783754-549787246 \\
549769608-549775894\end{array}$ & $\begin{array}{l}\text { WRKY DNA-binding protein 23, Asparagine } \\
\text { synthetase [glutamine-hydrolyzing] } 2\end{array}$ \\
\hline RSDW, RRDW & HORVU1Hr1G007930 & 1 & $\begin{array}{l}\text { L1H017313985, } \\
\text { L1H017313420, } \\
\text { L1H017313264 }\end{array}$ & $17203146-17207877$ & Receptor kinase 1 \\
\hline Rtillers, RRDW, RSDW & HORVU1Hr1G094990 & & L1H557218707 & $556905146-556910542$ & Protein kinase superfamily protein \\
\hline $\begin{array}{l}\text { Rleaves, RRL, Rtillers, } \\
\text { RRDW, RSDW, RSL }\end{array}$ & HORVU2Hr1G036250 & 2 & L2H160145958 & $159918998-159919803$ & $\begin{array}{l}\text { Zinc finger A20 and AN1 domain-containing } \\
\text { stress-associated protein } 9\end{array}$ \\
\hline RRDW, RSDW & HORVU2Hr1G023180 & 2 & $\begin{array}{l}\mathrm{C} 2 \mathrm{H} 68835493 \text {, } \\
\mathrm{C} 2 \mathrm{H} 68835922, \\
\mathrm{C} 2 \mathrm{H} 68836383\end{array}$ & $68833703-68836778$ & Protein FLOWERING LOCUS T \\
\hline $\begin{array}{l}\text { RSDW, RRDW, Rleaves, } \\
\text { Rtillers }\end{array}$ & HORVU3Hr1G116150 & 3 & $\begin{array}{l}\text { L3H695384685, } \\
\text { L3H695382868 }\end{array}$ & $695340362-695354154$ & BnaA01g30480D protein \\
\hline $\begin{array}{l}\text { Rleaves, Rtillers, RRDW, } \\
\text { RSDW, Rleaves, Rtillers }\end{array}$ & HORVU3Hr1G000420 & 3 & L3H001082150 & 1113533v1160560 & Serine/threonine-protein kinase ATM \\
\hline RRDW, RSDW & $\begin{array}{l}\text { HORVU3Hr1G098810, } \\
\text { HORVU3Hr1G098820 }\end{array}$ & 3 & D3H660063591 & $\begin{array}{l}660060877-660062773 \\
660072924-660073906\end{array}$ & $\begin{array}{l}\text { FAR1 family, putative, Glutathione S-transferase } \\
\text { family protein }\end{array}$ \\
\hline RRDW, RSDW & HORVU3Hr1G095880 & 3 & D3H650981422 & $651020620-651022321$ & NAC domain protein \\
\hline RRDW, RSDW & HORVU3Hr1G096720 & 3 & D3H654302848 & $654302473-654309516$ & Unknown function \\
\hline RRDW, RSDW & HORVU3Hr1G095090 & 3 & D3H649054975 & $649010625-649043473$ & MADS-box transcription factor family protein \\
\hline RRDW, RSDW & HORVU3Hr1G098610 & 3 & D3H659494414 & $659501460-659502707$ & $\begin{array}{l}\text { Leucine-rich repeat receptor-like protein kinase } \\
\text { family protein }\end{array}$ \\
\hline RRDW, RSDW & HORVU3Hr1G098920 & 3 & D3H660279535 & $660282090-660285460$ & Succinate dehydrogenase subunit 4 \\
\hline RRDW, RSDW & HORVU3Hr1G030580 & 3 & L3H147607703, & $147599908-147613052$ & Replication protein A $32 \mathrm{kDa}$ subunit B \\
\hline
\end{tabular}

Rleaves, Rtillers, RSDW Rtillers, RRDW, RSDW RRDW, RSDW RRDW, RSDW

Rtillers, Rleaves, RSDW RSDW, RRDW

Rleaves, Rtillers, RRDW, RSDW, RSL

Rleaves, Rtillers, RRDW, RSDW

RRDW, RSDW

RRDW, RSDW

Rleaves, Rtillers, RRDW,

RSDW

RSDW, RRDW

RSDW

RSDW

Rleaves, RRL, Rtillers, RRDW, RSDW, RSL Rleaves, Rtillers, RRDW, RSDW
HORVU3Hr1G015740 HORVU4Hr1G073520 HORVU4Hr1G012820 HORVU4Hr1G012940

HORVU4Hr1G035220 HORVU4Hr1G064820 HORVU5Hr1G000120

HORVU5Hr1G005910 L3H147607706, L3H147608174, L3H147608182

$3 \quad$ L3H037270607

$4 \quad\llcorner 4 \mathrm{H} 590243473$

$4 \quad$ L4H043542131

$4 \mathrm{~L} 4 \mathrm{H} 043655413$, L4H043655390

$4 \quad \mathrm{~L} 4 \mathrm{H} 258403614$

$4 \quad \mathrm{D} 4 \mathrm{H} 542586605$

$5 \quad$ L5H000409814

5 L5H009590416, L5H009590448, L5H009590411, L5H009590386, L5H009591047, L5H009590434

HORVU5Hr1G052600

HORVU5Hr1G052590

HORVU5Hr1G087040

HORVU5Hr1G119650 HORVU6Hr1G001200

HORVU6Hr1G069690

HORVU6Hr1G051370

HORVU6Hr1G051300
5 L5H411705586, L5H411705593

5 L5H411705586, L5H411705593

$5 \quad$ L5H577696873

$5 \quad$ L5H656383995

6 L6H004021832, L6H004021834

$6 \quad \mathrm{D} 6 \mathrm{H} 484044374$

$6 \quad$ L6H312413768

$6 \quad$ L6H312323946
37279795-37282055 590208225-590208651 43540550-43542049 43679183-43679901

257868981-257870162 542585648-542588347 441661-441901

9599498-9600567

411705218-411709576

411703643-411704235

577658366-577662325

656387855-656393736 3952786-3976837

484042599-484043907

312426934-312427189

312052625-312054058
Transcription factor GTE9

Auxin-induced protein 5NG4

Disease resistance protein RPM1

Unknown function

Unknown function

Protein NRT1/PTR FAMILY 8.3

Sucrose transporter 4

Late embryogenesis abundant protein D-34

Undescribed protein

B protein

Serine/threonine-protein kinase

Ethylene receptor

Receptor-like protein kinase 1

Basic helix-loop-helix (bHLH) DNA-binding superfamily protein

Unknown function

Glutathione reductase 
TABLE 4 | Continued

\begin{tabular}{|c|c|c|c|c|c|}
\hline Trait & Gene & Chr & Marker & Start-End & Annotation \\
\hline $\begin{array}{l}\text { Rleaves, Rtillers, RRDW, } \\
\text { RSDW }\end{array}$ & HORVU6Hr1G072350 & 6 & L6H502984487 & $502959206-502968928$ & $\begin{array}{l}\text { Sodium-coupled neutral amino acid transporter } \\
1\end{array}$ \\
\hline RRDW, RSDW & HORVU6Hr1G094720 & 6 & L6H581687061 & $581629386-581632269$ & Unknown function \\
\hline RRDW, RSDW & HORVU6Hr1G094650 & 6 & L6H581687061 & $581552566-581556341$ & Zinc finger $\mathrm{CCCH}$ domain-containing protein 19 \\
\hline RRDW, RSDW & HORVU6Hr1G003990 & 6 & L6H008899912 & $8892068-8893512$ & Undescribed protein \\
\hline RRDW, RSDW, Rtillers & HORVU7Hr1G088790 & 7 & L7H539446645 & $539205606-539206966$ & Ethylene-responsive transcription factor 11 \\
\hline RRDW, RSDW & HORVU7Hr1G105780 & 7 & $\begin{array}{l}\text { L7H617670049, } \\
\text { L7H617670050 }\end{array}$ & $617669550-617670231$ & Undescribed protein \\
\hline RSDW & HORVU7Hr1G098550 & 7 & C7H600147760 & $598424105-598497081$ & High-affinity nitrate transporter 2.7 \\
\hline $\begin{array}{l}\text { Rleaves, Rtillers, RRDW, } \\
\text { RSDW }\end{array}$ & HORVU7Hr1G095980 & 7 & $\begin{array}{l}\text { L7H585644789, } \\
\text { L7H585644784 }\end{array}$ & $585668738-585670356$ & UDP-Glycosyltransferase superfamily protein \\
\hline $\begin{array}{l}\text { Rleaves, Rtillers, RRDW, } \\
\text { RSDW }\end{array}$ & HORVU7Hr1G036070 & 7 & L7H082315424 & $82159514-82315426$ & 12-oxophytodienoate reductase 2 \\
\hline $\begin{array}{l}\text { Rleaves, Rtillers, RRDW, } \\
\text { RSDW }\end{array}$ & HORVU7Hr1G122350 & 7 & L7H655992857 & $655997675-655999540$ & $\begin{array}{l}\text { 2-oxoglutarate (2OG) and Fe (II)-dependent } \\
\text { oxygenase superfamily protein }\end{array}$ \\
\hline RSDW, RRDW & HORVU7Hr1G122800 & 7 & L7H655992885 & $657007676-657010806$ & Thionin-like peptide \\
\hline Rtillers, RSL & HORVU7Hr1G120820 & 7 & $\begin{array}{l}\text { L7H652578556, } \\
\text { L7H652581348 }\end{array}$ & & Unknown protein \\
\hline RSDW, RRDW, Rleaves & HORVU7Hr1G002010 & 7 & $\begin{array}{l}\text { L7H004018128, } \\
\text { L7H004018173, } \\
\text { L7H004018104, } \\
\text { L7H004016220 }\end{array}$ & $4019218-4024122$ & $\begin{array}{l}\text { Leucine-rich repeat receptor-like protein kinase } \\
\text { family protein }\end{array}$ \\
\hline RRDW, RSDW, RSL & HORVU7Hr1G114730 & 7 & $\begin{array}{l}\text { L7H640047456, } \\
\text { L7H640047457, } \\
\text { L7H640047480, } \\
\text { L7H640049188 }\end{array}$ & $640048567-640051420$ & F-box domain containing protein \\
\hline
\end{tabular}

Genes containing the significant markers or in close proximity to the markers are identified and listed as candidate genes. RSDW, relative shoot dry weight; RRDW, relative root dry weight; $R S L$, relative shoot length; RRL, Relative root length; Rtillers, Relative number of tillers; Rleaves, Relative number of leaves.

expression of nitrate transporters under high-N (Yu et al., 2015). The expression of basic helix loop helix TF bHLH120 in rice was also strongly induced by $\mathrm{N}$ deficiency (Hsieh et al., 2018).

In addition, two other candidate genes encoding leucine-rich repeat receptor-like kinases (LRR-RLKs) and one gene encoding receptor-like protein kinase 1 (RPK1) were located on barley chromosomes $3 \mathrm{H}, 7 \mathrm{H}$, and $6 \mathrm{H}$ respectively. In Arabidopsis, RPK1 was upregulated under stressful conditions; dehydration, low temperature, and high salt concentrations (Osakabe et al., 2005). This suggests that $R P K 1$ in barley might also respond in a similar fashion. Most of the functions of the LRR-RLKs are unknown, whereas well-characterized LRR-RLKs help in signal perception and plant growth (Osakabe et al., 2005). Expression of LRR-RLKs in response to low- $\mathrm{N}$ in crops has not been clearly reported.

Stress associated proteins such as A20/AN1 zinc-finger proteins regulate stress signaling in plants (Kothari et al., 2016). Dansana et al. (2014) reported improved water-deficit stress tolerance by overexpression of OsiSAP1, an A20/AN1 zincfinger protein in rice. Similarly, zinc finger $\mathrm{CCCH}$ family genes exhibited stress-responsive expression in Brassica rapa under salt and drought stress (Pi et al., 2018). This allows us to speculate that gene zinc finger $\mathrm{A} 20 / \mathrm{AN} 1 \mathrm{l}$ on $2 \mathrm{H}$ and the gene on $6 \mathrm{H}$ which is zinc finger $\mathrm{CCCH}$ domain-containing protein may play a potential role in low- $\mathrm{N}$ tolerance in barley.

High-affinity nitrate transporter 2.7 ( $H v N R T 2.7)$ was identified on chromosome $7 \mathrm{H}$ which is the functional homolog of AtNRT2.7 in Arabidopsis (69\% sequence identity). AtNRT2.7 showed only slight variation in its expression in root under $\mathrm{N}$ limiting conditions yet had a leaf specific expression. It could be involved in nitrate influx to keep the balance in leaves between the amount of nitrate used for assimilation and re-absorbed for further transport (Orsel et al., 2002). Results from Chopin et al. (2007) also demonstrate that AtNRT2.7 is expressed in leaves and necessary for seed nitrate accumulation. Atnrt2.7 mutants had an average of $50 \%$ nitrate reduction in seeds compared to the wild type. High affinity nitrate transporter OsNRT2.3b has been successfully overexpressed in barley transgenic lines to improve yield and nutrient uptake balance by Luo et al. (2020) using hydroponics with a nearly similar concentration of $\mathrm{N}$ to our study. Another NRT2 gene HvNRT2.1 was found to improve yield in Arabidopsis under low-N (Guo et al., 2020). Additionally, protein NRT1/PTR FAMILY 8.3 ( HvNRT1) gene HORVU4Hr1G064820 was identified on chromosome $4 \mathrm{H}$ under low-N and optimal-N supply but with a low threshold of $\mathrm{p}<0.0001$. It may be due to the limited number of traits scored for phenotyping. However, there are several previous findings in agreement with the results revealed from our study on NRT1 as a candidate (Huang et al., 2017; Wang W. et al., 2018; Hu et al., 2019; Zhang et al., 2019). Loss of function of OsNRT1.1A in rice exhibited a significant decrease in plant height, panicle size, seed setting rate, grain yield (by $\sim 80 \%$ than the wild type), whereas its overexpression led to increasing plant height, panicle size, seed number per panicle, biomass, chlorophyll content, yield (by $\sim 60 \%$ than the wild type) under low-N (Wang W. et al., 2018). OsNRT1.1A was therefore identified as a gene which can improve NUE and grain yield simultaneously in rice. (Protein sequence identity between OsNRT1.1A and HvNRT1 was $42 \%)$. This allows us to hypothesize these two nitrate transporters 
identified in barley are promising loci for NUE improvement. The other genes included in Table 4 have very less or no information reported related to NUE or low-N stress to the best of our knowledge and provides a strong background for further functional characterization and validation.

\section{CONCLUSION}

To improve nitrogen use efficiency in barley, unique genes and markers linked to low- $\mathrm{N}$ tolerance genes must be identified. Therefore, in the present study, we performed GWAS mapping within a set of genetically diverse barley accessions and identified significant MTAs for NUE. MTAs for RSDW, RRDW, RSL which expressed in both 2018 and 2019 were identified as stable MTAs that should be further explored for use in marker-assisted selection programs. Candidate gene pool provides a strong background for potential genetic manipulation in NUE improvement and open up avenues for further functional characterization. A highaffinity nitrate transporter 2.7 (HvNRT2.7) was discovered on chromosome $7 \mathrm{H}$ and found to associated with shoot and root dry weight. The MTAs and associated regions identified in this study are promising resources to guide further research aimed at improving and understanding NUE in barley.

\section{DATA AVAILABILITY STATEMENT}

The datasets analyzed and generated for this study are included in the article/Supplementary Material.

\section{AUTHOR CONTRIBUTIONS}

SK conducted the phenotyping experiments. SK and KC designed the hydroponics trial and performed statistical analysis. SK and GZ

\section{REFERENCES}

Abdel-Ghani, H. A., Sharma, R., Wabila, C., Dhanagond, S., Owais, S. J., Duwayri, M. A., et al. (2019). Genome-wide association mapping in a diverse spring barley collection reveals the presence of QTL hotspots and candidate genes for root and shoot architecture traits at seedling stage. BMC Plant Biol. 19 (216), 1-19. doi: 10.1186/s12870-019-1828-5

Anbessa, Y., and Juskiw, P. (2012). Review: Strategies to increase nitrogen use efficiency of spring barley. Can. J. Plant Sci. 92, 617-625. doi: 10.4141/ cjps2011-207

Beatty, P. H., Anbessa, Y., Juskiw, P., Carroll, R. T., Wang, J., and Good, A. G. (2010). Nitrogen use efficiencies of spring barley grown under varying nitrogen conditions in the field and growth chamber. Ann. Bot. 105 (7), 1171-1182. doi: $10.1093 / \mathrm{aob} / \mathrm{mcq} 025$

Benjamini, Y., and Hochberg, Y. (1995). Controlling the false discovery rate - a practical and powerful approach to multiple testing. J. R. Stat. Soc Ser. BMethodol. 57, 289-300. doi: 10.1111/j.2517-6161.1995.tb02031.x

Bradbury, P. J., Zhang, Z., Kroon, D. E., Casstevens, T. M., Ramdoss, Y., and Buckler, E. S. (2007). TASSEL: software for association mapping of complex traits in diverse samples. Bioinformatics 23, 2633-2635. doi: 10.1093/ bioinformatics/btm 308 conducted data analysis and interpretation. $\mathrm{CH}$ and $\mathrm{X}-\mathrm{QZ}$ generated the genotypic data. TA provided the seeds from his field experiments. CL, YH, and X-QZ conceived the project. SK drafted the manuscript with inputs from all authors.

\section{FUNDING}

This project was made possible by the generous support of Murdoch University and Department of Primary Industry and Regional Development Western Australia.

\section{ACKNOWLEDGMENTS}

We acknowledge the Western Australian State Agricultural Biotechnology Centre (SABC), Murdoch University and Western Barley Genetics Alliance (WBGA) for providing us with facilities to conduct the experiments. We appreciate WBGA researchers, Dr Tianhua He's advice in the haplotype analysis and Calum Watt's critical comments on the manuscript. We also thank Ms Lee-Anne McFawn from the Department of Primary Industries and Regional Development (DPIRD), Western Australia for her support in sorting out the seeds. Thanks are due to all members of WBGA especially Edward Mwando, Sharon Westcott, Rui Pan, Saipriyaa Vasan, Dandan Qin, Surendran, Le Xu, Meilin Zou, Jingye Chen, Nagmeh Nejat, Hao Luo, and Yonggang Wang for their extended support in harvesting.

\section{SUPPLEMENTARY MATERIAL}

The Supplementary Material for this article can be found online at: https://www.frontiersin.org/articles/10.3389/fpls.2020.571912/ full\#supplementary-material

Canas, R. A., Quillere, I., Lea, P. J., and Hirel, B. (2010). Analysis of amino acid metabolism in the ear of maize mutants deficient in two cytosolic glutamine synthetase isoenzymes highlights the importance of asparagine for nitrogen translocation within sink organs. Plant Biotechnol. J. 8 (9), 966-978. doi: 10.1111/j.1467-7652.2010.00524.x

Chien, S. H., Teixeirab, L. A., Cantarellab, H., Rehmc, G. W., Grantd, C. A., and Gearhart, M. M. (2016). Agronomic effectiveness of granular nitrogen/ phosphorus fertilizers containing elemental sulfur with and without ammonium sulfate: A review. Agron. J. 108, 1203-1213. doi: 10.2134/ agronj2015.0276

Chopin, F., Orsel, M., Dorbe, M. F., Chardon, F., Truong, H. N., Miller, A. J., et al. (2007). The Arabidopsis AtNRT2.7 nitrate transporter controls nitrate content in seeds. Plant Cell. 19 (5), 1590-1602. doi: 10.1105/tpc.107.050542

Curtis, T. Y., Bo, V., Tucker, A., and Halford, N. G. (2018). Construction of a network describing asparagine metabolism in plants and its application to the identification of genes affecting asparagine metabolism in wheat under drought and nutritional stress. Food Energy Secure 7 (1), 1-16. doi: 10.1002/fes3.126

Dansana, P. K., Kothari, K. S., Vij, S., and Tyagi, A. K. (2014). OsiSAP1 overexpression improves water-deficit stress tolerance in transgenic rice by affecting expression of endogenous stress-related genes. Plant Cell Rep. 33 (9), 1425-1440. doi: 10.1007/s00299-014-1626-3 
Evanno, G., Regnaut, S., and Goudet, J. (2005). Detecting the number of clusters of individuals using the software structure: a simulation study. Mol. Ecol. 14, 2611-2620. doi: 10.1111/j.1365-294X.2005.02553.x

Gao, S., Zhang, F., Zhi, Y., Chen, F., and Xiao, K. (2017). The yields, agronomic, and nitrogen use efficiency traits of wheat cultivars in north China under Nsufficient and deficient conditions. J. Plant Nutr. 40 (7), 1053-1065. doi: 10.1080/01904167.2016.1263328

Ghoneim, A. M., Gewaily, E. E., and Osman, M. M. A. (2018). Effects of nitrogen levels on growth, yield and nitrogen use efficiency of some newly released Egyptian rice genotypes. Open Agric. 3 (1), 310-318. doi: 10.1515/opag-2018-0034

Glass, A. D. M., Britto, D. T., Kaiser, B. N., Kinghorn, J. R., Kronzucker, H. J., Kumar, A., et al. (2002). The regulation of nitrate and ammonium transport systems in plants. J. Exp. Bot. 53, 855-864. doi: 10.1093/jexbot/53.370.855

Goel, P., Sharma, N. K., Bhuria, M., Sharma, V., Chauhan, R., and Pathania, S. (2018). Transcriptome and co-expression network analyses identify key genes regulating nitrogen use efficiency in Brassica juncea L. Sci. Rep. 8 (7451), 1-18. doi: 10.1038/s41598-018-25826-6

Guo, B., Li, Y., Wang, S., Li, D., Lv, C., and Xu, R. (2020). Characterization of the nitrate transporter gene family and functional identification of HvNRT2.1 in barley (Hordeum vulgare L.). PLoS One 15 (4), 1-15. doi: 10.1371/ journal.pone.0232056

Han, Y., Yin, S. Y., Huang, L., Wu, X., Zeng, J., Liu, X., et al. (2018). A sodium transporter HvHKT1;1 confers salt tolerance in barley via regulating tissue and cell ion homeostasis. Plant Cell Physiol. 59 (10), 1976-1989. doi: 10.1093/pcp/ pcy116

Hao, Q. N., Zhou, X. A., Sha, A. H., Wang, C., Zhou, R., and Chen, S. L. (2011). Identification of genes associated with nitrogen-use efficiency by genome-wide transcriptional analysis of two soybean genotypes. BMC Genomics 12 (525), 115. doi: 10.1186/1471-2164-12-525

Hazzouri, K. M., Khraiwesh, B., Amiri, K. M. A., Pauli, D., Blake, T., Shahid, M., et al. (2018). Mapping of HKT1;5 gene in barley using GWAS approach and its implication in salt tolerance mechanism. Front. Plant Sci. 9, 156 (156). doi: $10.3389 /$ fpls.2018.00156

$\mathrm{He}, \mathrm{X}$., Qu, B., and Li, W. (2015). The nitrate-inducible NAC transcription factor TaNAC2-5A controls nitrate response and increases wheat yield. Plant Physiol. 169, 1991-2005. doi: 10.1104/pp.15.00568

He, H., Yang, R., Li, Y., Ma, A., Cao, L., Wu, X., et al. (2017). Genotypic variation in nitrogen utilization efficiency of oilseed rape (Brassica napus) under contrasting $\mathrm{N}$ supply in pot and field experiments. Front. Plant Sci. 8, 1825. doi: $10.3389 /$ fpls.2017.01825

Hill, C. B., Angessa, T. T., McFawn, L., Wong, D., Tibbits, J., Zhang, X., et al. (2019a). Hybridisation-based target enrichment of phenology genes to dissect the genetic basis of yield and adaptation in barley. Plant Biotechnol. J. 17 (5), 932-944. doi: 10.1111/pbi.13029

Hill, C. B., Wong, D., Tibbits, J., Forrest, K., Hayden, M., Zhang, X. Q., et al. (2019b). Targeted enrichment by solution-based hybrid capture to identify genetic sequence variants in barley. Sci. Data 6 (1), 12. doi: 10.1038/s41597019-0011-z

Hill, C. B., Angessa, T. T., Zhang, X. Q., Chen, K., Zhou, G., Tan, C., et al. (2020). A global barley panel revealing genomic signatures of breeding in modern cultivars. bioRxiv. doi: 10.1101/2020.03.04.976324

Hoffmann, A., Maurer, A., and Pillen, K. (2012). Detection of nitrogen deficiency QTL in juvenile wild barley introgression lines growing in a hydroponic system. BMC Genet. 13 (88), 1-15. doi: 10.1186/1471-2156-13-88

Hsieh, P., Kan, C., Wu, H., Yang, H. C., and Hsieh, M. H. (2018). Early molecular events associated with nitrogen deficiency in rice seedling roots. Sci. Rep. 8 (12207), 1-23. doi: 10.1038/s41598-018-30632-1

Hu, M., Zhao, X., Liu, Q., Hong, X., Zhang, W., Zhang, Y., et al. (2018). Transgenic expression of plastidic glutamine synthetase increases nitrogen uptake and yield in wheat. Plant Biotechnol. J. 16, 1858-1867. doi: 10.1111/ pbi. 12921

Hu, B., Jiang, Z., Wang, W., Qiu, Y., Zhang, Z., Liu, Y., et al. (2019). NitrateNRT1.1B-SPX4 cascade integrates nitrogen and phosphorus signalling networks in plants. Nat. Plants 5 (4), 401-413. doi: 10.1038/s41477-0190384-1

Huang, S., Zhao, C., Zhang, Y., and Wang, C. (2017). Nitrogen use efficiency in rice, in Nitrogen in Agriculture-Updates. Eds. K. Amanulla and S. Fahad (London, United Kingdom: IntechOpen), 187-208.
Hubisz, M. J., Falush, D., Stephens, M., and Pritchard, J. K. (2009). Inferring weak population structure with the assistance of sample group information. Mol. Ecol. Resour. 9, 1322-1332. doi: 10.1111/j.1755-0998.2009.02591.x

Jabbari, M., Fakheri, B. A., Aghnoum, R., Nezhad, N. M., and Ataei, R. (2018). GWAS analysis in spring barley (Hordeum vulgare $\mathrm{L}$.) for morphological traits exposed to drought. PLoS One 13 (9), 1-22. doi: 10.1371/journal.pone.0204952

Jiang, L., Ball, G., Hodgman, C., Coules, A., Zhao, H., and Lu, C. (2018). Analysis of gene regulatory networks of maize in response to nitrogen. Genes 9 (3), 1-20. doi: 10.3390/genes 9030151

Kessel, B., Schierholt, A., and Becker, H. C. (2012). Nitrogen use efficiency in genetically diverse set of winter oilseed rape (Brassica napus L.). Crop Sci. 52 , 2546-2554. doi: 10.2135/cropsci2012.02.0134

Kindu, G. A., Tang, J., Yin, X., and Struik, P. C. (2014). Quantitative trait locus analysis of nitrogen use efficiency in barley (Hordeum vulgare L.). Euphytica 199 (1-2), 207-221. doi: 10.1007/s10681-014-1138-9

Kothari, K. S., Dansana, P. K., Giri, J., and Tyagi, A. K. (2016). Rice stress associated protein 1 (OsSAP1) interacts with aminotransferase (OsAMTR1) and pathogenesis-related 1a protein (OsSCP) and regulates abiotic stress responses. Front. Plant Sci. 7, 1057 (1057). doi: 10.3389/fpls.2016.01057

Kowalski, A. M., Gooding, M., Ferrante, A., Slafer, G. A., Orford, S., Gasperini, D., et al. (2016). Agronomic assessment of the wheat semi-dwarfing gene Rht8 in contrasting nitrogen treatments and water regimes. Field Crops Res. 191, 150160. doi: $10.1016 /$ j.fcr.2016.02.026

Law, H. M., Wong, P., Chan, H. K., Yam, K. M., Chen, L., Chow, C. M., et al. (2003). Overexpression of the ASN1 gene enhances nitrogen status in seeds of Arabidopsis. Plant Physiol. 132 (2), 926-935. doi: 10.1104/pp.103.020123

Li, P., Chen, F., Cai, H., Liu, J., Pan, Q., Liu, Z., et al. (2015). A genetic relationship between nitrogen use efficiency and seedling root traits in maize as revealed by QTL analysis. J. Exp. Bot. 66 (11), 3175-3188. doi: 10.1093/ jxb/erv127

Li, X., Zhou, Z., Ding, J., Wu, Y., Zhou, B., Wang, R., et al. (2016). Combined linkage and association mapping reveals QTL and candidate genes for plant and ear height in maize. Front. Plant Sci. 7, 833. doi: 10.3389/fpls.2016.00833

Liu, Z. G., Gao, K., Shan, S., Gu, R. C., Wang, Z. K., Craft, E. J., et al. (2017). Comparative analysis of root traits and the associated QTLs for maize seedlings grown in paper roll, hydroponics and vermiculite culture system. Front. Plant Sci. 8, 436 (436). doi: 10.3389/fpls.2017.00436

Luo, B., Xu, M., Zhao, L., Xie, P., Chen, Y., Harwood, W., et al. (2020). Overexpression of the high affinity nitrate transporter OsNRT2.3b driven by different promoters in barley improves yield and nutrient uptake balance. Int. J. Mol. Sci. 21, (4) 1-(4)15. doi: 10.3390/ijms21041320

Martin, A., Lee, J., Kichey, T., Gerentes, D., Zivy, M., Tatout, C., et al. (2006). Two cytosolic glutamine synthetase isoforms of maize are specifically involved in the control of grain production. Plant Cell 18, 3252-3274. doi: 10.1105/ tpc. 106.042689

Mickelson, S., See, D., Meyer, F. D., Garner, J. P., Foster, C. R., Blake, T. K., et al. (2003). Mapping of QTL associated with nitrogen storage and remobilization in barley (Hordeum vulgare L.) leaves. J. Exp. Bot. 54 (383), 801-812. doi: 10.1093/jxb/erg084

Moll, R. H., Kamprath, E. J., and Jackson, W. A. (1982). Analysis and interpretation of factors which contribute to efficiency of nitrogen utilization. Agron. J. 74, 562-564. doi: 10.2134/agronj1982.00021962007400030037x

Monostori, I., Szira, F., Tondelli, A., Arendas, T., Gierczik, K., Cattivelli, L., et al. (2017). Genome-wide association study and genetic diversity analysis on nitrogen use efficiency in a Central European winter wheat (Triticum aestivum L.) collection. PLoS One 12 (12), 1-32. doi: 10.1371/journal.pone.0189265

Mwando, E., Han, Y., Angessa, T. T., Zhou, G., Hill, C. B., Zhang, X., et al. (2020). Genome-wide association study of salinity tolerance during germination in barley (Hordeum vulgare L.). Front. Plant Sci. 11, 118. doi: 10.3389/fpls.2020.00118

Neeraja, C. N., Voleti, S. R., Subrahmanyam, D., Surekha, K., and Rao, P. R. (2019). Breeding for rice nitrogen use efficiency. Indian J. Genet. 79 (1), 208-215. doi: 10.31742/IJGPB.79S.1.11

Orsel, M., Krapp, A., and Daniel-Vedele, F. (2002). Analysis of the NRT2 nitrate transporter family in Arabidopsis. Structure and gene expression. Plant Physiol. 129 (2), 886-896. doi: 10.1104/pp.005280

Osakabe, Y., Maruyama, K., Seki, M., Satou, M., Shinozaki, K., and YamaguchiShinozaki, K. (2005). Leucine-rich repeat receptor-like kinasel is a key membrane-bound regulator of abscisic acid early signaling in Arabidopsis. Plant Cell 17 (4), 1105-1119. doi: 10.1105/tpc.104.027474 
Pasam, R. K., Sharma, R., Malosetti, M., Eeuwijk, F. A. V., Haseneyer, G., Kilian, B., et al. (2012). Genome-wide association studies for agronomical traits in a worldwide spring barley collection. BMC Plant Biol. 12, 1-22. doi: 10.1186/ 1471-2229-12-16

Pathak, R. R., Ahmad, A., Lochab, S., and Raghuram, N. (2008). Molecular physiology of plant nitrogen use efficiency and biotechnological options for its enhancement. Curr. Sci. 94, 1394-1403.

Pathak, R. R., Lochab, S., and Raghuram, N. (2011). "Plant systems: Improving plant nitrogen-use efficiency," in Comprehensive Biotechnology. Ed. M. MooYoung (Pergamon: Elsevier), 209-218.

Pauli, D., Muehlbauer, G. J., Smith, K. P., Cooper, B., Hole, D., Obert, D. E., et al. (2014). Association mapping of agronomic QTLs in U.S. spring barley breeding germplasm. Plant Genome 7, 1-15. doi: 10.3835/plantgenome2013. 11.0037

Pham, A., Maurer, A., Pillen, K., Brien, C., Dowling, K., Berger, B., et al. (2019). Genome-wide association of barley plant growth under drought stress using a nested association mapping population. BMC Plant Biol. 134, 1-16. doi: 10.1186/s12870-019-1723-0

Pi, B., He, X., Ruan, Y., Jang, J. C., and Huang, Y. (2018). Genome-wide analysis and stress-responsive expression of $\mathrm{CCCH}$ zinc finger family genes in Brassica rapa. BMC Plant Biol. 18 (373), 1-15. doi: 10.1186/s12870-018-1608-7

Poourkheirandish, M., and Komatsuda, T. (2007). The importance of barley genetics and domestication in a global perspective. Ann. Bot. 100 (5), 9991008. doi: 10.1093/aob/mcm 139

Postma, J. A., Dathe, A., and Lynch, J. P. (2014). The optimal lateral root branching density for maize depends on nitrogen and phosphorus availability. Plant Physiol. 166, 590-602. doi: 10.1104/pp.113.233916

Ranjitha, K. M. S., Biradar, S., Desai, S. A., Naik, V. R., Bhat, S., Satisha, T. N., et al. (2017). Media standardization for hydroponic culture to screen wheat genotypes for nitrogen use efficiency. Int. J. Curr. Microbiol Appl. Sci. 6 (12), 2814-2820. doi: 10.20546/ijcmas.2017.612.327

Risch, N., and Merikangas, K. (2007). The future of genetic studies of complex human diseases. Science 273, 1516-1517. doi: 10.1126/science.273.5281.1516

Safina, S. A. (2010). Effect of nitrogen levels on grain yield and quality of some barley genotypes grown on sandy soil and salinity irrigation. Egypt J. Agronomy. 32 (2), 207-222.

Selvaraj, M. G., Valencia, M. O., Ogawa, S., Lu, Y., Wu, L., Downs, C., et al. (2017). Development and field performance of nitrogen use efficient rice lines for Africa. Plant Biotechnol. J. 15, 775-787. doi: 10.1111/pbi.12675

Shrawat, A. K., Carroll, R. T., DePauw, M., Taylor, G. J., and Good, A. G. (2008). Genetic engineering of improved nitrogen use efficiency in rice by the tissuespecific expression of alanine aminotransferase. Plant Biotechnol. J. 6, 722-732. doi: 10.1111/j.1467-7652.2008.00351.x

Sigua, G. C., Stone, K. C., Bauer, P. J., and Szogi, A. A. (2018). Biomass and nitrogen use efficiency of grain sorghum with nitrogen and supplemental irrigation. Agron. J. 110 (3), 1119-1127. doi: 10.2134/agronj2017.09.0533

Stahl, A., Vollrath, P., Samans, B., Frisch, M., Wittkop, B., and Snowdon, R. J. (2019). Effect of breeding on nitrogen use efficiency associated traits in oilseed rape. J. Exp. Bot. 70 (6), 1969-1986. doi: 10.1093/jxb/erz044

Sun, J. J., Guo, Y., Zhang, G. Z., Gao, M. G., Zhang, G. H., Kong, F. M., et al. (2013). QTL mapping for seedling traits under different nitrogen forms in wheat. Euphytica 191 (3), 317-331. doi: 10.1007/s10681-012-0834-6

Tang, W., Ye, J., Yao, X., Zhao, P., Xuan, W., Tian, Y., et al. (2019). Genome-wide associated study identifies NAC42-activated nitrate transporter conferring high nitrogen use efficiency in rice. Nat. Commun. 10 (5279), 1-11. doi: 10.1038/s41467-019-13187-1
Tian, H., Smet, I. D., and Ding, Z. (2014). Shaping a root system: regulating lateral versus primary root growth. Trends Plant Science 19 (7), 426-431. doi: 10.1016/ j.tplants.2014.01.007

Visioni, A., Tondelli, A., Francia, E., Pswarayi, A., Malosetti, M., Russell, J., et al. (2013). Genome-wide association mapping of frost tolerance in barley (Hordeum vulgare L.). BMC Genomics 14 (424), 1-13. doi: 10.1186/14712164-14-424

Wang, M., Jiang, N., Jia, T., Leach, L., Cockram, J., Comadran, J., et al. (2012). Genome-wide association mapping of agronomic and morphologic traits in highly structured populations of barley cultivars. Theor. Appl. Genet. 124, 233246. doi: 10.1007/s00122-011-1697-2

Wang, Q., Nian, J., Xie, X., Yu, H., Zhang, J., Bai, J., et al. (2018). Genetic variations in ARE1 mediate grain yield by modulating nitrogen utilization in rice. Nat. Commun. 9 (735), 1-10. doi: 10.1038/s41467-017-02781-w

Wang, W., Hu, B., Yuan, D., Liu, Y., Che, R., Hu, Y., et al. (2018). Expression of the nitrate transporter gene OsNRT1.1A/OsNPF6.3 confers high yield and early maturation in rice. Plant Cell. 30 (3), 638-651. doi: 10.1105/tpc.17.00809

Watt, C., Zhou, G., McFawn, L. A., Chalmers, K. C., and Li, C. (2019). Fine mapping of qGL5H, a major grain length locus in barley (Hordeum vulgare L.). Theor. Appl. Genet. 132 (4), 883-893. doi: 10.1007/s00122-018-3243-y

Xiong, H., Guo, H., Zhou, C., Guo, X., Xie, Y., Zhao, L., et al. (2019). A combined association mapping and t-test analysis of SNP loci and candidate genes involving in resistance to low nitrogen traits by a wheat mutant population. PLoS One 14 (1), 1-15. doi: 10.1371/journal.pone.0211492

Yang, L., Hu, H., Zhu, B., Jin, X., Wu, F., and Zhang, G. P. (2014). Genotypic variations of nitrogen use efficiency in Tibetan wild and cultivated barleys. J. Zhejiang Univ. 40 (2), 155-164. doi: 10.3785/j.issn.1008-9209

Yang, J., Worley, E., Toress-Jerez, I., Miller, R., Wang, M., Fu, C., et al. (2015). $P v N A C 1$ and $P v N A C 2$ are associated with leaf senescence and nitrogen use efficiency in switchgrass. Bioenergy Res. 8 (2), 868-880. doi: 10.1007/s12155014-9566-X

Yu, C., Liu, Y., Zhang, A., Su, S., Yan, A., Huang, L., et al. (2015). MADS-box transcription factor OsMADS25 regulates root development through affection of nitrate accumulation in rice. PLoS One 10 (8), 1-15. doi: 10.1371/ journal.pone.0135196

Zhan, A., and Lynch, J. P. (2015). Reduced frequency of lateral root branching improves $\mathrm{N}$ capture from low-N soils in maize. J. Exp. Bot. 66, 2055-2065. doi: 10.1093/jxb/erv007

Zhang, G., Xu, N., Chen, H., Wang, G., and Huang, J. (2018). OsMADS25 regulates root system development via auxin signalling in rice. Plant J. 95, 1004-1022. doi: $10.1111 /$ tpj.14007

Zhang, J., Liu, Y., Zhang, N., Hu, B., Jin, T., Xu, H., et al. (2019). NRT1.1B is associated with root microbiota composition and nitrogen use in field-grown rice. Nat. Biotechnol. 37 (6), 676-684. doi: 10.1038/s41587-019-0104-4

Conflict of Interest: The authors declare that the research was conducted in the absence of any commercial or financial relationships that could be construed as a potential conflict of interest.

Copyright (C) 2020 Karunarathne, Han, Zhang, Zhou, Hill, Chen, Angessa and Li. This is an open-access article distributed under the terms of the Creative Commons Attribution License (CC BY). The use, distribution or reproduction in other forums is permitted, provided the original author(s) and the copyright owner(s) are credited and that the original publication in this journal is cited, in accordance with accepted academic practice. No use, distribution or reproduction is permitted which does not comply with these terms. 